\title{
Oxidative response of polymorphonuclear leucocytes to synovial fluids from patients with rheumatoid arthritis
}

\author{
B Dularay, J S Badesha, P A Dieppe, C J Elson
}

\begin{abstract}
Only a minority $(7 / 35,20 \%)$ of synovial fluids from patients with rheumatoid arthritis (RA) and none from patients with other arthritides stimulated the oxidative response of polymorphonuclear leucocytes (PMNs). Superoxide anion generation was measured by superoxide dismutase inhibitable reduction of cytochrome $c$. The same synovial fluids stimulated superoxide release by $P M N s$ regardless of their source, though they elicited a greater response from $R A$ synovial fluid PMNs than from either RA blood PMNs or blood PMNs from normal subjects. The remaining synovial fluids failed to stimulate any of the PMNs, though some $(2 / 10)$ stimulated PMNs pretreated with cytochalasin $B$. The stimulatory activity was removed from RA synovial fluids by protein A-Sepharose and eluted with the void volume on gel chromatography. It is considered that immunoglobulin aggregates in some RA synovial fluids may stimulate the oxidative response of PMNs in the joint space but that most do not because these fluids contain either a specific inhibitor or immunoglobulin aggregates of an inappropriate type, or both.
\end{abstract}

Polymorphonuclear leucocytes (PMNs) are found in large numbers ${ }^{1}$ in the synovial fluids of patients with rheumatoid arthritis (RA) together with high concentrations of immunoglobulin aggregates. ${ }^{2-4}$ As aggregated immunoglobulins are known to stimulate PMNs to release superoxide anions in vitro ${ }^{5-7}$ it seems reasonable to suggest that the production of superoxide anions by PMNs will be stimulated by such aggregates in rheumatoid synovial fluids, and therefore be produced in vivo. Indeed, a number of authors have suggested that superoxide anions are produced by neutrophils in RA joints and contribute to tissue damage. $^{8-12}$ There is little evidence that RA synovial fluids can stimulate PMNs to generate such products, however. Our report describes experiments which test the ability of RA synovial fluids to stimulate the release of superoxide anions from RA synovial fluid and RA blood PMNs as well as from blood PMNs from normal subjects.

\section{Patients and methods}

PATIENTS

Sixty patients (40 female (mean age 58); 20 male (mean age 57)) fulfilling the standard criteria for classical or definite RA were studied. They were receiving a variety of non-steroidal antiinflammatory and slow acting antirheumatic drugs. Synovial fluids were obtained by therapeutic aspiration of inflamed joints which were free from bacterial infection. Samples were collected in 0.1 volume of acid citrate dextrose and centrifuged to remove the cells. The synovial fluids were divided into aliquots and stored at $-70^{\circ} \mathrm{C}$.

Synovial fluids were also obtained from four patients with osteoarthritis, four with psoriatic arthritis, and four with pyrophosphate arthropathy.

\section{PMN PREPARATION}

Peripheral blood from normal subjects or patients with RA was collected in $3 \cdot 8 \%$ sodium citrate. The PMNs were isolated by sedimentation on dextran and density gradient separation in Percoll as described by Dooley and colleagues. ${ }^{13}$ This yielded a preparation of $98 \%$ PMNs as judged by Wright's stain with $<0 \cdot 1 \%$ monocyte contamination as judged by nonspecific esterase staining. ${ }^{14}$ For both blood and synovial fluid the yield of PMNs was between 55 and $75 \%$. Polymorphonuclear leucocytes were isolated from synovial fluid in the same way omitting dextran sedimentation.

\section{ASSAY OF SUPEROXIDE ANIONS}

Superoxide anion generation was measured by superoxide dismutase inhibitable reduction of cytochrome $c^{15}$ using a recording double beam spectrophotometer. Sample and reference cuvettes contained $10^{6} \mathrm{PMNs}$ and $1 \cdot 2 \mathrm{mg}$ cytochrome $c$ (horse heart type III; Sigma) in 1 ml Hanks's balanced salt solution (Gibco). The reference cuvette in addition contained $500 \mu \mathrm{g}$ superoxide dismutase (bovine erythrocyte; Sigma). The stimulatory agent was added to both cuvettes and the reduction of cytochrome $c$ monitored at $550 \mathrm{~nm}$ for 5-10 minutes. (The rates expressed, however, are maximal and occurred within the first two minutes of the reaction.) Nanomoles superoxide were calculated using an extinction coefficient of $21 \cdot 1$ $\mathrm{mM} / \mathrm{cm}$. The stimulatory agents used were synovial fluid (10-200 $\mu \mathrm{l}), N$-formyl-methionylleucyl-phenylalanine (FMLP), and heat aggregated IgG. FMLP (Sigma) was dissolved in dimethyl sulphoxide and stored as a $1 \mathrm{mM}$ stock solution at $-70^{\circ} \mathrm{C}$. IgG was prepared from human serum, ${ }^{16}$ adjusted to a protein concen- 
tration of $30 \mathrm{mg} / \mathrm{ml}$ and heated at $63^{\circ} \mathrm{C}$ for 30 minutes.

In some experiments PMNs were pretreated with cytochalasin B. Polymorphonuclear leucocytes were incubated with $20 \mu \mathrm{g} / \mathrm{ml}$ cytochalasin B (Sigma; dissolved in dimethyl sulphoxide) for 10 minutes at room temperature before the ability of synovial fluids to stimulate their oxidative response was measured.

\section{SEPHAROSE-PROTEIN A CHROMATOGRAPHY}

IgG and IgG aggregates were removed from synovial fluid by affinity chromatography as described by Goudswaard et al. ${ }^{17}$ Synovial fluid was incubated with hyaluronidase (Sigma; bovine, $100 \mathrm{units} / \mathrm{ml}$ of fluid) for 15 minutes at $37^{\circ} \mathrm{C}$ and centrifuged at $12000 \mathrm{~g}$ for two minutes. The fluid was diluted 1 in 2 with phosphate buffered saline, $\mathrm{pH} 7 \cdot 3$, and applied to a column of Sepharose-protein A CL-4B (Sigma). The eluate was assayed for the presence of IgG with radial immunodiffusion kits (Serotec). As a control for non-specific removal of protein, synovial fluid was treated with Sepharose CL-4B (the matrix to which protein $A$ is attached).

\section{SEPARATION OF SYNOVIAL FLUID BY GEL CHROMATOGRAPHY}

Synovial fluid was digested with hyaluronidase, diluted 1 to 1 with phosphate buffered saline and applied to a $2.6 \times 100 \mathrm{~cm}$ column of ACA34 (LKB). The eluate was collected in $6 \mathrm{ml}$ fractions at a flow of $5 \mathrm{ml} /$ hour over 24 hours. The column had previously been calibrated using molecular weight markers in the range $14 \cdot 5-150 \mathrm{kD}$ and the void volume determined with dextran blue.

\section{Results}

OXIDATIVE RESPONSE OF PMNS TO

SYNOVIAL FLUIDS

The oxidative response of normal blood PMNs to synovial fluids obtained from patients with

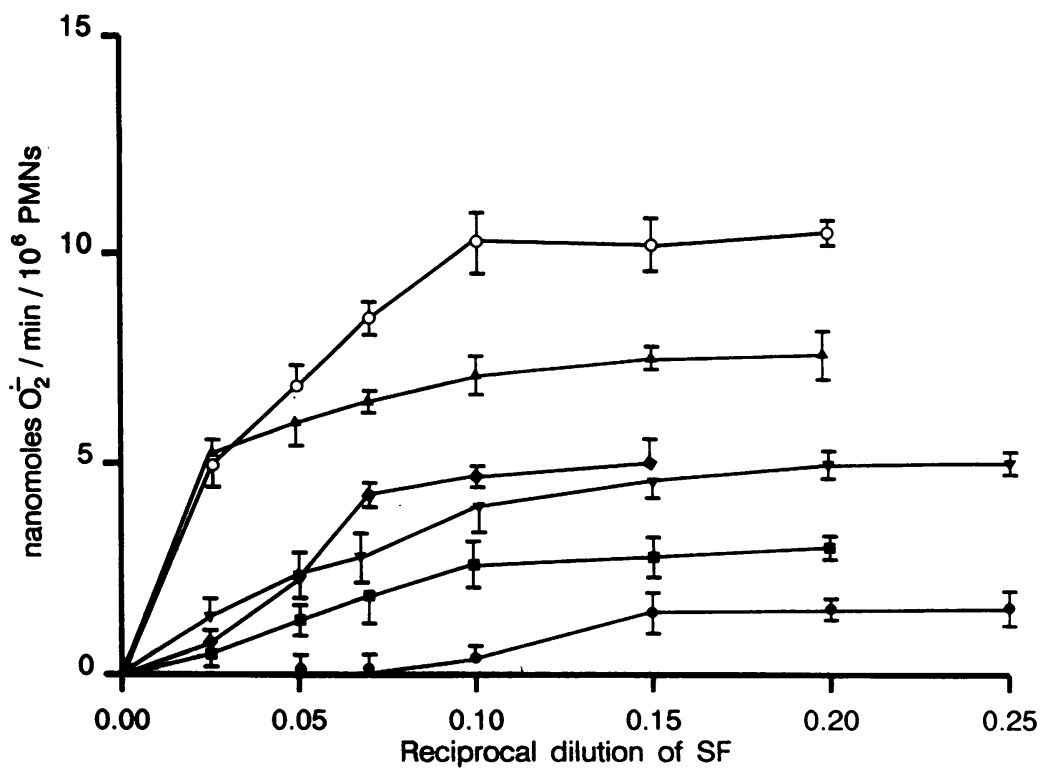

Figure 1 Oxidative response of normal blood polymorphonuclear leucocytes (PMNs) to increasing concentrations of rhewmatoid arthritis synovial fluids. The results are the mean (SD) of three measurements. Each symbol denotes one patient's synovial fluid.
RA or other arthritides was determined. In all, only $7 / 47$ fluids tested stimulated the PMNs to release superoxide anions, though the test PMNs responded to stimulation with heat aggregated IgG and FMLP. All the stimulatory synovial fluids were from patients with $R A$, and fig 1 shows the oxidative response of the PMNs to six of these fluids. Each synovial fluid induced a response dependent on dose, which reached a maximum at $10-20 \%$.

Polymorphonuclear leucocytes from RA synovial fluid may respond to synovial fluid constituents which fail to elicit responses from blood PMNs. Accordingly, a comparison was made between the response of paired RA synovial fluid and blood PMNs and normal blood PMNs to heterologous synovial fluid. The PMNs were stimulated with increasing concentrations of synovial fluids $(2 \cdot 5-25 \% \mathrm{v} / \mathrm{v})$. Thirty five fluids (including five of the seven synovial fluids shown to stimulate normal blood PMNs) were tested on three paired RA blood and synovial fluid samples and on normal blood PMNs. As can be seen from table 1, five of the synovial fluids at one concentration $(10 \% \mathrm{v} / \mathrm{v})$ stimulated the release of superoxide anions from both blood and synovial fluid PMNs, and in each case the response of the synovial fluid PMNs was higher than that of the blood PMNs (RA and normal). Similar results were obtained at other concentrations. The remainder of the synovial fluids stimulated none of the PMNs.

In a further experiment the oxidative response of synovial fluid and paired blood PMNs from five patients with RA and of blood PMNs from 10 normal donors to one stimulatory synovial fluid $(10 \% \mathrm{v} / \mathrm{v})$ was measured. The mean (SD) response of the RA synovial fluid PMNs was $18 \cdot 6$ (4), of the paired blood PMNs $7 \cdot 2(1)$, and of the normal blood PMNs $6.8(0.8)$ nanomoles superoxide anions/minute $/ 10^{6} \mathrm{PMNs}$.

The oxidative response of RA synovial fluid and paired blood PMNs to 15 autologous synovial fluids was also tested. In all but two of these cases there was no measurable release of superoxide anions by the PMNs. Of the two, the response of the first patient's synovial fluid PMNs to their own fluid $(10 \% \mathrm{v} / \mathrm{v})$ was 5.4 $(0.3)$ and of their blood PMNs $3 \cdot 2(0.8)$, and the response of the second patient's synovial fluid PMNs to their own fluid was $2.5(0.5)$ and of their blood PMNs 2.8 $(1.0)$ nanomoles superoxide anions/minute $/ 10^{6}$ PMNs. These two fluids, but none of the others, also stimulated heterologous RA and normal PMNs.

Table 1 Oxidative response of polymorphonuclear leucocytes (PMNs) from rheumatoid arthritis $(R A)$ synovial fluid (SF), RA blood, and normal blood to heterologous $R A$ synovial fluids. Results are the means $(S D)$ of iriplicate determinations

\begin{tabular}{|c|c|c|c|}
\hline \multirow{2}{*}{$\begin{array}{l}\text { Symovial } \\
\text { fluid* }\end{array}$} & \multicolumn{3}{|c|}{ Nanomoles superoxide/min $/ 10^{6} P M N s$} \\
\hline & $\begin{array}{l}\text { RA SF } \\
P M N s\end{array}$ & $\begin{array}{l}\text { RA blood } \\
\text { PMNs }\end{array}$ & $\begin{array}{l}\text { Normal } \\
\text { blood PMNs }\end{array}$ \\
\hline $\begin{array}{l}1 \\
2 \\
3 \\
4 \\
5\end{array}$ & $\begin{array}{r}15.0(2.0) \\
20.2(1.8) \\
12.4(1.0) \\
9.0(1.5) \\
11.0(1.2)\end{array}$ & $\begin{array}{l}6.4(0.9) \\
3.5(1.2) \\
4.8(1.6) \\
4.0(0.5) \\
\text { NTt }\end{array}$ & $\begin{array}{r}7 \cdot 1(1 \cdot 0) \\
10.1(0.5) \\
3.4(0.2) \\
4.7(0.2) \\
2.8(0.2)\end{array}$ \\
\hline
\end{tabular}

*Synovial fluids from five patients with RA. $+\mathbf{N T}=$ not tested. 
EFFECT OF CYTOCHALASIN B ON OXIDATIVE RESPONSE TO SYNOVIAL FLUIDS

Cytochalasins are widely used to augment the response of PMNs to stimuli. ${ }^{18}$ It It wondered, therefore, whether the response of normal blood PMNs might be augmented by cytochalasin B so that they would respond to low concentrations of stimulatory agents in synovial fluids. Normal blood PMNs were pretreated with cytochalasin $B$ and their oxidative response to RA synovial fluids, which had failed to stimulate the response of noncytochalasin B PMNs, was measured. Two of the ten fluids tested stimulated superoxide production, and the results for these fluids are shown in table 2. It can be seen that the effect was not linearly related to the concentration of synovial fluid.

\section{IDENTITY OF STIMULATORY AGENT IN RA SYNOVIAL FLUID}

As a first step towards determining the identity of the stimulatory agent in synovial fluid the response to heat $\left(56^{\circ} \mathrm{C}\right.$ for 30 minutes) and hyaluronidase treatment of synovial fluid stimulatory activity was studied, but no effect was seen. Thus, for example, the oxidative response of normal blood PMNs to one stimulatory synovial fluid was 9.5 nanomoles superoxide/ minute/ $10^{6}$ PMNs, 9.1 after heating, and $9 \cdot 4$ after hyaluronidase treatment and to a second stimulatory synovial fluid was 6.6 nanomoles superoxide/minute/ $10^{6} \mathrm{PMNs}, 6 \cdot 1$ after heating, and 6.6 after hyaluronidase digestion.

As immunoglobulin aggregates are potent stimulators of the oxidative response and are known to be present in RA synovial fluid the effect of removing such aggregates from synovial fluids on their stimulatory activity was measured. Three of the stimulatory synovial fluids were affinity chromatographed on either Sepharoseprotein A or Sepharose alone and their ability to stimulate oxidative responses of normal blood PMNs tested. Table 3 shows that whereas most

Table 2 Oxidative response of cytochalasin $B$ pretreated polymorphomuclear leucocytes (PMNs) to symovial fluids (SFs)

\begin{tabular}{lll}
\hline $\begin{array}{l}\text { Symovial fluid } \\
(\%)\end{array}$ & \multicolumn{2}{l}{ Nanomoles superoxide/min/106 PMNs } \\
\cline { 2 - 3 } & $S F 1^{*}$ & $S F 2$ \\
\hline 2.5 & 1.2 & $2 \cdot 1$ \\
5.0 & 3.6 & 3.4 \\
10.0 & 2.3 & 2.7 \\
20.0 & 1.5 & 1.9
\end{tabular}

"SF1, SF2=RA synovial fluids.

The results are the means of two experiments; each experiment was carried out in duplicate.

Table 3 Oxidative response of normal blood polymorphomuclear leucocytes (PMNs) to symovial fluids (SFs) before and afier the specified treatment

\begin{tabular}{lrrr}
\hline Treatment & \multicolumn{3}{c}{ Nanomoles superoxide/min/106 PMNs* } \\
\cline { 2 - 4 } & $S F 1$ & $S F 2$ & $S F 3$ \\
\hline Whole SF & 6.6 & 9.0 & 5.1 \\
Sepharose-protein A & $<0.5$ & $<0.5$ & $<0.5$ \\
Sepharose CL-4B & 4.2 & 6.0 & 3.2 \\
\hline
\end{tabular}

*All values are the means of two experiments in which two measurements were made. Cells were stimulated with $10 \%(v / v)$ synovial fluid or synovial fluid treated as specified.

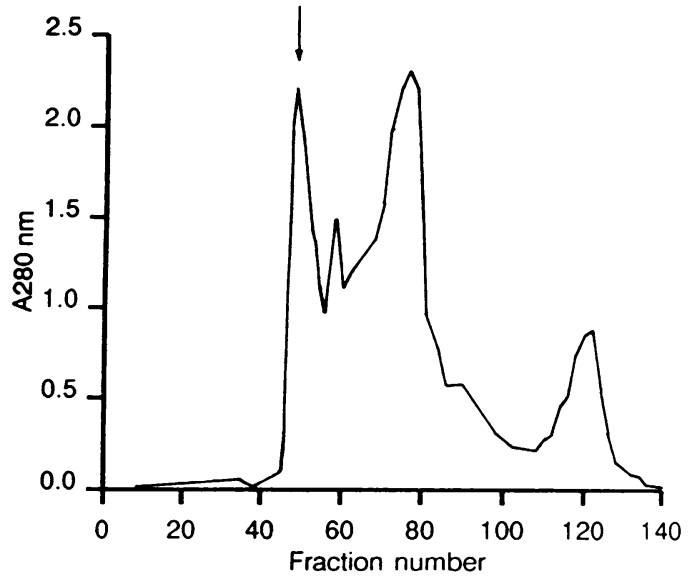

Figure 2 A stimulatory synovial fluid was fractionated on $A C A 34$ and the absorbance at $280 \mathrm{~nm}$ of the eluate against fraction number is shown.

of the stimulatory activity of untreated synovial fluid was retained after Sepharose treatment, it was lost after affinity chromatography on Sepharose-protein A. To confirm that the test PMNs respond to IgG aggregates they were stimulated with either heat aggregated or nonaggregated IgG. The mean (SD) response to heat aggregated IgG $(75 \mu \mathrm{g} / \mathrm{ml})$ was $2 \cdot 7(1 \cdot 2)$ (range $0.9-2.8)$ but no response $(<0.5$ nanomoles superoxide anions/minute/ $10^{6}$ PMNs) was elicited by non-aggregated IgG at the same or higher concentrations.

In another experiment synovial fluids were separated by gel chromatography and the fractions tested for their ability to stimulate PMN oxidative respones. Figure 2 shows the elution profile of one stimulatory synovial fluid. Only one fraction-namely, that corresponding to the void volume, stimulated superoxide release. Similar results were obtained with another stimulatory synovial fluid. By contrast, separation of non-stimulatory synovial fluids yielded no fraction which stimulated the generation of superoxide by PMNs.

\section{Discussion}

The main finding reported here is that only a minority of rheumatoid synovial fluids, and none from patients with other arthritides, stimulate superoxide production by PMNs. These results do not necessarily disagree with previous work which showed that a much larger proportion of RA synovial fluids stimulated PMNs to produce a luminol enhanced chemiluminescence response. ${ }^{20}$ It is known that this response is dependent on a myeloperoxidase mediated reaction and not directly on superoxide release. ${ }^{21}$ Thus the activity observed by Gale and his colleagues was a measure of both degranulation and superoxide release. We have previously shown that many RA synovial fluids stimulate PMN degranulation, ${ }^{22}$ resulting in the release of myeloperoxidase, and presumably these fluids will also stimulate a chemiluminescence response. By contrast, the assay used here was a direct measure of superoxide release and would not detect the products of degranulation responses.

The occurrence of IgG aggregates in the 
rheumatoid joint space is well reported..$^{2-4}$ As aggregates of this type are potent stimuli of superoxide generation by PMNs in vitro we examined the possibility that the stimulatory activity of the synovial fluids was due to such aggregates. The removal of IgG, including IgG aggregates, from the synovial fluids led to loss of superoxide anion generating activity and as monomeric IgG was shown, by this and other studies, ${ }^{23}$ not to elicit superoxide anions from PMNs it seems reasonable to conclude that the loss of activity is due to the removal of IgG aggregates. Additionally, both stimulatory and non-stimulatory synovial fluids were fractionated according to size, but only stimulatory synovial fluids yielded a fraction that stimulated superoxide release. The stimulatory activity was restricted to a high molecular weight fraction, which again is consistent with the presence of IgG aggregates.

Immunoglobulin aggregates are found in most synovial fluids, ${ }^{2-4}$ yet only a fraction of the fluids stimulate superoxide release. There are at least two explanations for these observations. Firstly, the size and concentration of immunoglobulin aggregates are known to determine both the nature and the magnitude of the response elicited, with large insoluble immunoglobulin aggregates being potent stimulators of superoxide release. ${ }^{23-25}$ Secondly, synovial fluids contain an activity which specifically inhibits aggregated IgG stimulated superoxide production. ${ }^{26}$ The activity was found in most synovial fluids and both RA and normal serum.

Products arising from the interaction of superoxide radicals with cellular and synovial fluid components have been detected in synovial fluids. ${ }^{27-29}$ Thus it is perhaps surprising that only a small number of synovial fluids stimulate PMNs to release superoxide anions. It might be argued that the true number of stimulatory fluids is higher because PMNs pretreated with cytochalasin B did respond to some synovial fluids that failed to elicit a response from untreated PMNs (either normal or RA). It is known, however, that PMNs pretreated with cytochalasin B, unlike untreated PMNs, will respond to a variety of chemotactic agents, ${ }^{19}$ some of which are known to be present in synovial fluids. ${ }^{30}$ Another explanation is that only immunoglobulin aggregates deposited at tissue surfaces, but not those in synovial fluid, stimulate PMNs. Alternatively, immunoglobulin aggregates, able to stimulate PMNs to release superoxide, may not be continuously present in synovial fluids. Finally, superoxide anions may be generated by cells other than PMNs.

This work was supported by the MRC. B Dularay was in receipt of a SERC CASE studentship in collaboration with Roussel Laboratories.

1 Palmer D G. Total leukocyte enumeration in pathogenic synovial fluids. Am ₹ Clin Pathol 1968; 49: 812-4.

2 Winchester R J, Agnello R F, Kunkel H G. Gammaglobulin complexes in synovial fluids of patients with rheumatoid complexes in synovial fluids of patients with rheumatoid complement levels. Clin Exp Immunol 1970; 6: 689-706.

3 Male D K, Roitt I M, Hay F C. Analysis of immune Male D K, Roitt I M, Hay F C. Analysis of immune
complexes in synovial effusions of patients with rheumatoid arthritis. Clin Exp Immunol 1980; 39: 297-306.
4 Bedwell A E, Elson C J, Carter S D, Dieppe P A, Hutton C W, Czudek R. Isolation and analysis of complement activating aggregates from synovial fluid of patients with rheumatoid arthritis. Ann Rheum Dis 1987; 46: 55-64.

5 Goldstein I M, Roos D, Kaplan H B, Weissman G. Complement and immunoglobulins stimulate superoxide production by human leukocytes independently of phagoproduction by human leukocytes independe

6 Henson P M, Oades Z G. Stimulation of human neutrophils by soluble and insoluble immunoglobulin aggregates. Secretion of granule constituents and increased oxidation of glucose. F Clin Invest 1975; 56: 1053-61.

7 Weiss S J, Ward P A. Immune complex induced generation of oxygen metabolites by human neutrophils. F Immunol 1982; 129: 309-13.

8 Burkhardt $H$, Schwingel M, Menninger M, Macartney $H$ W, Tschesche $H$. Superoxide radicals as effectors of cartilage destruction. Arthritis Rheum 1986; 29: 379-87.

9 Greenwald R A, May W W. Effect of oxygen-derived free radicals on hyaluronic acid. Arthritis Rheum 1980; 23: radicals

10 Weiss S J, Peppin G, Ortiz Z, Ragsdale C, Test S T. Oxidative inactivation of latent collagenase by human neutrophils. Science 1985; 227: 747-9.

11 Weiss S J, Regiani S. Neutrophils degrade subendothelial matrices in the presence of alpha-1-proteinase inhibitor. Cooperative use of lysosomal proteinases and oxygen metabolites. $\mathcal{F}$ Clin Invest 1984; 73: 1297-303.

12 McCord J M, Wong K. Phagocyte produced free radicals: roles of cytotoxicity and inflammation. In: Oxygen free radicals and tissue damage. Amsterdam: Elsevier/Excerpta Medica/North Holland, 1979: 343-60. (Ciba Foundation Symposium, No 65.)

13 Dooley D C, Simpson J F, Meryman H T. Isolation of large numbers of fully viable human neutrophils: a preparative technique using Percoll density gradient centrifugation. Exp Hematol 1982; 10: 591-9.

14 Ennist D L, Jones K H. Rapid method for identification of macrophages in suspension by acid alpha-naphthyl acetate esterase activity. $\mathcal{F}$ Histochem 1983; 31: $960-3$

15 Babior B M, Kipnes R S, Carnutte J T. Biological defence mechanisms. The production by leukocytes of superoxide a potential bactericidal agent. 7 Clin Invest 1973; 52: 741-4.

16 Wright J F, Hunter W M. A convenient replacement for cyanogen bromide activated solid phases by immunoradiometric assays. F Immunol Methods 1982; 48: 311-26.

17 Goudswaard J, Van Der Donk J A, Noordzij A, Van Dam R, Vaerman J P. Protein A reactivity of various mammalian immunoglobulins. Scand f Immunol 1978; 8: 21-8.

18 Zurier R B, Hoffstein S, Weissman G. Cytochalasin B: effect on lysosomal enzyme release from human polymorphonuclear leukocytes. Proc Natl Acad Sci USA 1973; 70: 844-8.

19 Dewald B, Baggiolini M. Activation of NADPH oxidase in human neutrophils. Synergism between FMLP and the neutrophil products PAF and $\mathrm{LTB}_{4}$. Biochem Biophys Res Commun 1985; 128: 297-304.

20 Gale R, Bertouch J V, Bradley J, Roberts-Thomson P J. Direct activation of neutrophil chemiluminescence on rheumatoid sera and synovial fluid. Ann Rheum Dis 1983; 42: $158-62$.

21 DeChatelet I R, Long G D, Shirley P S, Thomas M J, Henderson $F W$, Cohen $M$ S. Mechanism of luminol dependent chemiluminescence of human neutrophils. I Immunol 1982; 129: 1589-93.

22 Dularay B, Elson C J, Dieppe P A. Depressed degranulation response of synovial fluid polymorphonuclear leukocytes from patients with rheumatoid arthritis to IgG aggregates. Clin Exp Immunol 1990; 79: 195-201.

23 Starkebaum G, Stevens D L, Henry C, Gavin S E. Stimulation of neutrophil chemiluminescence by soluble immune complexes and antibodies to neutrophils. $\mathcal{F ~ L a b}$ Clin Med 1981; 98: 280-91.

24 Henson P M, Johnson H B, Spiegelberg H L. The release of granule enzymes from human neutrophils stimulated by granule enzymes from human neutrophils stimulated by aggregated immunoglobulins of different

25 Ward P A, Duque R E, Sulavik M C, Johnson K J. In vitro and in vivo stimulation of rat neutrophils and alveola macrophages by immune complexes. Am f Pathol 1983 110: 297-309.

26 Dularay B, Elson C J, Dieppe P A. Enhanced oxidative response of polymorphonuclear leukocytes from synovia luids of patients with rheumatoid arthritis. Autoimmunity 1988; 1: 159-69.

27 Lunec J, Halloran S P, White A G, Dormandy T L. Free radical oxidation (peroxidation) products in serum and synovial fluid in rheumatoid arthritis. $\mathcal{F}$ Rheumatol 1981; 8: $233-45$.

28 Rowley D A, Gutteridge J M C, Blake D R, Farr M Halliwell $B$. Lipid peroxidation in rheumatoid arthritis: thiobarbiturate acid reactive material and catalytic iron salts in synovial fluid from patients with rheumatoid salts in synovial fluid from patien
arthritis. Clin Sci 1984; 66: 691-5.

29 Winyard P G, Blake D R, Chirico S, Gutteridge J M C Lunec J. Mechanism of exacerbation of rheumatoid synovitis by total dose iron dexacerbation of rheumatoid synovitis by total dose iron dextran infusion: in vivo demonstra-

30 Klickstein L B, Shapleigh C, Goetzl E J. Lipoxygenation of lickstein L B, Shapleigh C, Goetzl E J. Lipoxygenation of arachidonic acid as a source of polymorphonuclear leukocyte chemotactic factors in synovial fluid and tissue in heumatoid arthritis and spondyloarthritis. $\mathcal{f}$ Clin Inves 1980; 66: 1166-70. 